\title{
Correction to: GPU Accelerated Successive Interference Cancellation for NOMA Uplink with User Clustering
}

\author{
Talgat Manglayev ${ }^{1}$ (D) Refik Caglar Kizilirmak ${ }^{1}$ - Yau Hee $\mathrm{Kho}^{2} \cdot$ \\ Nor Asilah Wati Abdul Hamid ${ }^{3}$ \\ Published online: 7 August 2018 \\ (C) Springer Science+Business Media, LLC, part of Springer Nature 2018
}

\section{Correction to: Wireless Personal Communications https://doi.org/10.1007/s11277-018-5915-y}

There was a typo in the second author's name in the initial online publication. The original article has been corrected.

The original article can be found online at https://doi.org/10.1007/s11277-018-5915-y.

Talgat Manglayev

talgat.manglayev@nu.edu.kz

Refik Caglar Kizilirmak

refik.kizilirmak@nu.edu.kz

Yau Hee Kho

yauhee.kho@vuw.ac.nz

Nor Asilah Wati Abdul Hamid asila@upm.edu.my

1 School of Engineering, Nazarbayev University, Astana, Kazakhstan Z05H0P9

2 School of Engineering and Computer Science, Victoria University of Wellington, Wellington 6140, New Zealand

3 Faculty of Computer Science and Information Technology, Universiti Putra Malaysia, 43400 Serdang, Selangor, Malaysia 